ritis and Metabolic Diseases, who gave valuable advice in the statistical analysis of these data.

\section{REFERENCES}

Allison, A. C., and ap Rees, W. (1957). Brit. med. f., 2, 1137. Bayani-Sioson, P. S., Louch, J., Sutton, H. E., Neel, J. V., Horne, S. L., and Gershowitz, H. (1962). Amer. 7. hum. Genet., 14, 210 Beckman, L. (1959). Lancet, 2, 952.

Beckman, L. (1959). Lancet, 2, 952. J., and Jayle, M.-F. (1964). C.R. Acad. Sci. (Paris), 259, 3875.

Connell, G. E., Dixon, G. H., and Smithies, O. (1962). Nature (Lond.), 193505.

Dublin, T. D., Bernanke, A. D., Pitt, E. L., Massell, B. F., Allen, F. H., jun., and Amezcua, F. (1964). Brit. med. F., 2, 775 .

Galatius-Jensen, F. (1958). Acta genet. (Basel), 8, 248.

Jayle, M.-F., and Moretti, J. (1962). Progr. Hemat., 3, 352.

Laurell, C.-B., and Grönvall, C. (1962). Advanc. clin. Chem., 5, 135. Nance, W. E., and Smithies, O. (1963). Nature (Lond.), 198, 869.
Nyman, M. (1959). Scand. 7. clin Lab. Invest., 11, Suppl. No. 39 Owen, J. A., Smith, R., Padyani, R., and Martin, J. (1964). Clin. Sci. 26, 1.

Parker, W. C., and Bearn, A. G. (1961). Ann. hum. Genet., 25, 227.

Polonovski, M., and Jayle, M.-F. (1940). C.R. Acad. Sci. (Paris), 211 517

Poulik, M. D. (1957). Nature (Lond.), 180, 1477.

Robson, E. G., Glen-Bott, A. M., Cleghorn, T. E., and Harris, H. (1964). Ann. hum. Genet., 28, 77.

Shinton, N. K., Richardson, R. W., and Williams, J. D. F. (1965). 7 clin. Path., 18, 114.

Smith, H., and Owen, J. A. (1961). Biochem. f., 78, 723.

Smithies, O. (1955). Ibid., 61, 629.

Sutton, H. E., and Karp, G. W., jun. (1964). Amer. F. hum. Genet., 16, 419.

Whitten, C. F. (1961). Amer. f. Dis. Child., 102, 480.

Workman, P. L., Blumberg, B. S., and Cooper, A. J. (1963). Amer. F. hum. Genet., $15,429$.

Yamaguchi, M., Nakajima, H., and Yamaoka, K. (1961). Proc. Jap. Acad., 37, 584.

\title{
Folic-acid Deficiency in Rheumatoid Arthritis : Relation of Levels of Serum Folic-acid Activity to Treatment with Phenylbutazone
}

\author{
D. J. DELLER,* M.R.A.C.P ; E. URBAN,* M.R.A.C.P. ; R. N. IBBOTSON,* M.C.P.A. \\ JIINNIFER HORWOOD,* B.SC. ; S. MILAZZO,* M.R.A.C.P. ; H. N. ROBSON,* F.R.C.P.ED.
}

Brit. med. F., 1966, 1, 765-767

Anaemia is a well-recognized complication of rheumatoid arthritis. The anaemia is usually hypochromic and normocytic, and, though the mechanism responsible for its production is obscure, factors such as ineffective utilization of iron for erythropoiesis, haemolysis, and alimentary bleeding are probably important (Roy et al., 1955 ; Alexander et al., 1956). Macrocytic anaemia was considered rare until Partridge and Duthie (1963) reviewed the haematological data of more than 2,000 patients with the disease. They found megaloblastic anaemia in $1.38 \%$ of patients with rheumatoid arthritis compared with $0.27 \%$ in patients attending their clinic for other diseases with musculo-skeletal symptoms. Though Partridge and Duthie (1963) considered that deficiency of vitamin $B_{12}$ was the cause of the megaloblastic anaemia, Gough et al. (1964) found evidence of folic-acid deficiency in other patients with this disease.

Gough et al. (1964) assessed the folic-acid status of 46 patients with rheumatoid arthritis by microbiological assay of serum folic-acid activity and the estimation of the urinary excretion of formimino-glutamic acid (Figlu). Low serum levels of folic-acid activity were found in one-third of patients, and biochemical evidence of folic-acid deficiency in the form of increased excretion of Figlu was found in nearly threequarters of them. These authors excluded from their survey patients taking anticonvulsant drugs, barbiturates, and phenylbutazone, because these drugs had been reported to produce megaloblastic anaemia (Mannheimer et al., 1952; Badenoch, 1954 ; Hawkins and Meynell, 1958 ; Robson and Lawrence, 1959). The case of megaloblastic anaemia following the administration of phenylbutazone reported in the literature was from this unit. However, as this patient has since developed alcoholic cirrhosis, and because no further reports of the development of megaloblastic anaemia following the administration of this drug have appeared in the literature, a study of the effect of phenylbutazone on folic-acid metabolism has been made. The serum levels of folic-acid activity were estimated in two groups of patients with rheumatoid arthritis, one receiving treatment with

* From the Department of Medicine, University of Adelaide, the Institute of Medical and Veterinary Science, and the Queen Elizabeth Hospital, Adelaide, South Australia. phenylbutazone and the other not receiving this drug. The results were also compared with those from patients with other forms of arthritis and rheumatism, both treated and untreated, and with results from normal people.

\section{Material and Methods}

Eighty patients (58 women, 22 men) were studied. Fifty had received phenylbutazone or oxyphenbutazone for at least three months and 30 had not been treated with these drugs for more than one year. There were 21 patients with rheumatoid arthritis in the treated group and 20 in the non-treated group. The remaining patients had a variety of diagnoses: osteoarthritis, intervertebral disk degeneration, gout, ankylosing spondylitis, and Paget's disease.

Each patient was examined and details of the duration and activity of the disease, drugs used in treatment, and dietary habits recorded. Blood was taken for haematological studieshaemoglobin estimation, red-cell indices, and blood film (Dacie, 1956), serum lovel of folic-acid activity (Herbert, 1961), and serum level of vitamin $B_{12}$ (Hutner et al., 1956).

\section{Results}

Serum Folic-acid Actioity.-The distribution of the levels of serum folic-acid activity is shown in Fig. 1. The level of serum folic-acid activity in 60 normal subjects ranged from 2.3 to $18.6 \mathrm{~m} \mu \mathrm{g} . / \mathrm{ml}$., with a mean of $7.5 \mathrm{~m} \mu \mathrm{g} . / \mathrm{ml}$. Levels of 2 $\mathrm{m} / \mathrm{gg} / \mathrm{ml}$. or lower were found in 13 of 41 patients with rheumatoid arthritis $(31.7 \%)$. Of the patients with reduced levels eight were receiving phenylbutazone or oxyphenbutazone (eight of 21 , or $38.1 \%$ ), and five were not (five of 20 , or $25 \%$ ). This difference was not statistically significant $(P>0.05)$. The means of the levels of serum folic acid in patients with rheumatoid arthritis treated with phenylbutazone $(3 \mathrm{~m} \mu \mathrm{g} . / \mathrm{ml}$.) and not treated $(3.2 \mathrm{~m} \mu \mathrm{g} . / \mathrm{ml}$.) were also not significantly different. However, as a group the levels of patients with rheumatoid arthritis were significantly lower than those of the normal subjects. 
Patients with joint and rheumatic conditions other than rheumatoid arthritis had levels of serum folic-acid activity which were similar to those in normal subjects, and treatment with phenylbutazone did not alter these levels.

Relation of Serum Folic-acid Activity and Anaemia.-In the patients with rheumatoid arthritis there was no close correlation

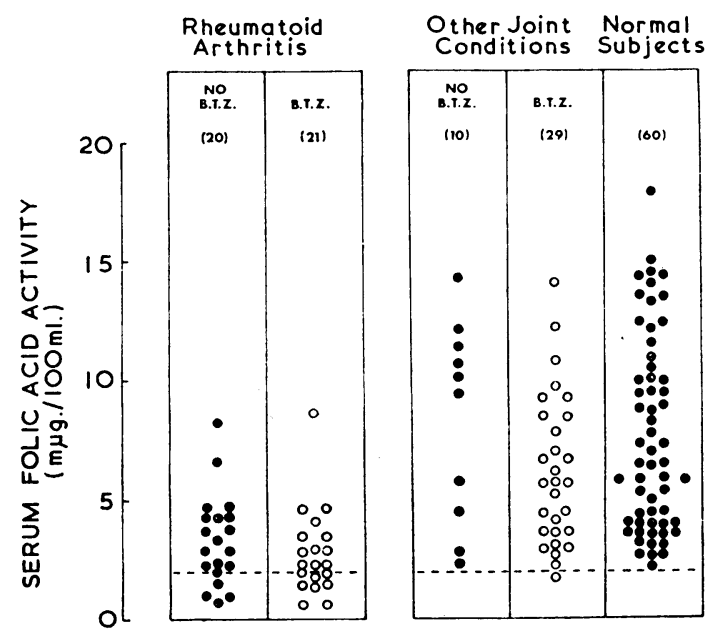

FIG. 1.-Serum levels of folic-acid activity in patients with various forms of arthritis and in normal subjects. B.T.Z. signifies treatment with either phenylbutazone or oxyphenbutazone.

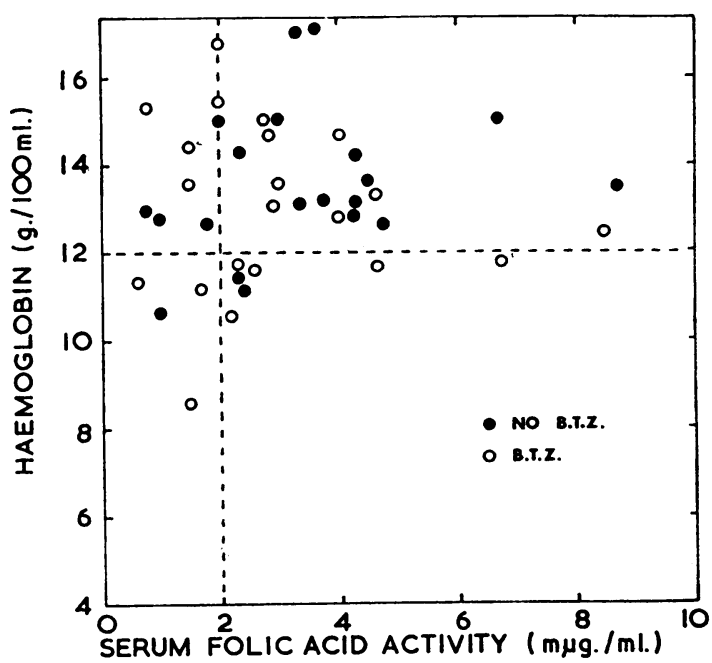

FIG. 2-Relation of haemoglobin levels and levels of serum folic-acid activity in 41 patients with rheumatoid arthritis.

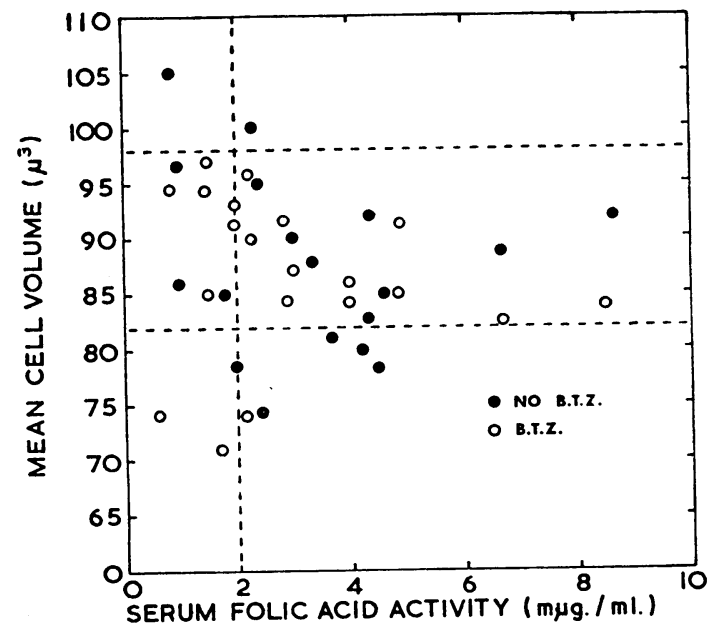

FIG. 3.-Relation of red eell size and levels of serum folicacid activity in patients with rheumatoid arthritis. between serum levels of folic-acid activity and either the haemoglobin level (Fig. 2) or the mean cell volume (Fig. 3). Only four of 11 patients with haemoglobin concentrations less than $12 \mathrm{~g} . / 100 \mathrm{ml}$. had low serum folic-acid levels. Also the anaemia was macrocytic in only one of 13 patients.

Relation of Serum Folic-acid Activity and Other Data.Analysis of the clinical data of patients with rheumatoid arthritis and low serum levels of folic-acid activity did not show any relationship between the folic-acid status and the duration and severity of the arthritis, treatment with salicylates and corticosteroids, or the dietary history. However, the intake of salicylates and corticosteroids was considerably greater in the patients with rheumatoid arthritis as a group than in the patients with the other disorders.

Serum Vitamin $B_{12}$ Level. - The serum level of vitamin $B_{12}$ was within the normal range in every patient examined.

\section{Discussion}

This study has confirmed the finding of Gough et al. (1964) that levels of serum folic-acid activity are frequently reduced in patients with rheumatoid arthritis. Some further information was added: that treatment with phenylbutazone, which could possibly inhibit the metabolic functions of folic acid, does not influence the serum-folate levels; that reduced serum levels are not necessarily accompanied by macrocytosis of the red cells; and that normal levels are found in joint and musculo-skeletal disorders other than rheumatoid arthritis.

Robson and Lawrence (1959) reported a case of folic-acid responsive megaloblastic anaemia which appeared to follow the administration of phenylbutazone. On the analogy that certain of the anticonvulsant drugs and barbiturates can cause folic-acid deficiency, and because of the structural similarities between these drugs and phenylbutazone, it was suggested that phenylbutazone might also cause a disturbance in folic-acid metabolism. We now consider this complication unlikely for three reasons. Firstly, we could not demonstrate a specific association of treatment with phenylbutazone and low serum folic-acid levels, whereas subnormal serum-folate levels have been observed in one-half of subjects taking anticonvulsant agents (Klipstein, 1964). Secondly, no additional reports of megaloblastic anaemia following treatment with phenylbutazone have been reported in the literature in spite of the frequent use of this drug in clinical practice (McCarthy and Chalmers, 1964). Lastly, the patient reported by Robson and Lawrence (1959) was subsequently recognized by them to have a nutritional folic-acid deficiency.

The striking feature of this study was the frequency of low values for serum folic-acid activity in patients with rheumatoid arthritis. Thirteen of 41 patients $(32 \%)$ with rheumatoid arthritis had $L$. casei folate levels of less than $2.1 \mathrm{~m} \mu \mathrm{g} . / \mathrm{ml}$. Gough et al. (1964) studied 46 patients with the disease and found $65 \%$ had low or subnormal levels and $33 \%$ had severely reduced levels in the range of patients with megaloblastic anaemia. The mechanism of reduced serum-folate levels in rheumatoid arthritis is uncertain. An inadequate dietary intake of folic acid and increased demands for the vitamin have been considered important (Gough et al., 1964). However, though individual patients with rheumatoid arthritis may take an unsatisfactory diet, no significant difference in folic-acid intake between patients and control subjects has been found (Gough et al., 1964). In the present study the dietary history of patients with rheumatoid arthritis was similar to that of patients with other forms of arthritis and rheumatism. Folic-acid deficiency could also result from demands of the vitamin exceeding the supply. Increased utilization of folic acid might result from the accelerated erythropoiesis resulting from alimentary blood loss and haemolysis, or from the consumption of folic acid by rapidly proliferating joint tissue, or possibly from a stimulating effect of salicylates and adrenocortical hormones on folic-acid 
metabolism. Though the patients with rheumatoid arthritis in this study received larger quantities of salicylates and prednisone and for longer periods of time than patients with other disorders, the role of increased utilization of folic acid remains speculative for the present time.

The relationship between reduced serum-folate levels and the anaemia of rheumatoid arthritis is also problematical. In the present study there was no correlation between reduced levels of serum folic-acid activity and either anaemia or macrocytosis. It is therefore unlikely that folic-acid deficiency is important in the mechanism of anaemia in this condition, though a controlled clinical trial of folic-acid therapy is probably indicated. There is certainly no experimental or clinical evidence to suggest that the disturbance in folic-acid metabolism has a more fundamental significance in the pathogenesis of the rheumatoid process itself.

\section{Summary}

An investigation of the haematological effects of phenylbutazone in patients with various forms of arthritis has demonstrated no inhibitory effect of this drug on folic-acid metabolism. Thirty-two per cent. of patients with rheumatoid arthritis had low serum-folate levels, and normal levels were found in other joint and rheumatic conditions.

\section{REFERENCES}

Alezander, W. R. M., Richmond, J., Roy, L. M. H., and Duthie, J. J. R. (1956). Ann. rheum. Dis., 15, 12.

Badenoch, J. (1954). Proc. roy. Soc. Med., 47, 426.

Dacie, J. V. (1956). Practical Haematology, 2nd ed. Churchill, London. Gough, K. R., McCarthy, C., Read, A. E., Mollin, D. L., and Waters, A. H. (1964). Brit. med. 7., 1, 212.

Hawkins, C. F., and Meynell, M. J. (1958). Quart. Y. Med., 27, 45.

Herbert, V. (1961). 7. clin. Invest., 40, 81.

Hutner, S. H., Bach, M. K., and Ross, G. I. M. (1956). F. Protozool., 3, 101 .

Klipstein, F. A. (1964). Blood, 23, 68.

Mannheimer E. Pakesch F., Reimer, E. E., and Vetter, H. (1952). Med. Klin., 47, 2, 1397.

McCarthy, D. D., and Chalmers, T. M. (1964). Canad. med. Ass. F., 90, 1061 .

Partridge, R. E. H., and Duthie, J. J. R. (1963). Brit. med. F., 1, 89.

Robson, H. N., and Lawrence, J. R. (1959). Ibid., $2,475$.

Roy, L. M. H., Alexander, W. R. M., and Duthie, J. J. R. (1955). Ann. rheum. Dis., 14, 63.

\title{
Need for a "Team Approach" to Clinical and Research Problems of Children's Tumours*
}

\author{
J. K. STEWARD, $†$ M.D., M.R.C.P., D.C.H.
}

Brit. med. F., 1966, 1, 767-770

The Manchester Children's Tumour Registry was started in 1953 and in the first 10 years 998 cases were included. All the patients were under 15 years old and lived in the Manchester Hospital Region; and there is reason to believe that over $90 \%$ coverage was obtained. This means that 100 out of a population of a million children develop tumours each year. The frequency of the various neoplasms is most easily expressed as their annual incidence in the region. This is shown in Table I.

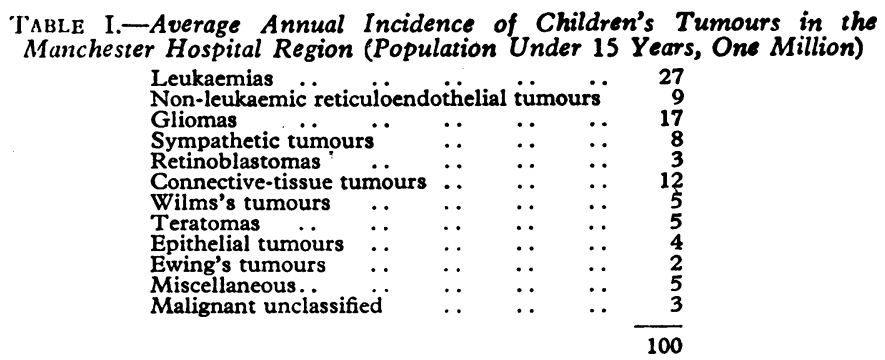

In December 1964 the condition of the 894 children included in the Registry up to September 1962 was assessed. Altogether 616 of these 894 cases have already proved fatal, giving a mortality rate of $69 \%$. The outcome of the various types of tumours is shown in Table II.

Is the high mortality inevitable? In this paper it is emphasized that children with tumours are being cared for in a hospital system which was not designed for their special needs and which in fact does not allow the optimal use of thera-

* Paper presented to the Section of Paediatrics of the Royal Society of Medicine at a Symposium on Malignant Disease in Childhood on 22 January 1965.

t Lecturer in Charge of the Children's Tumour Registry, Departments of Child Health and Pathology, Manchester University. peutic methods that are available now or may become available in the future. TABLE II.-Prognosis of Various Types of Tumours in the 894 Children
Included in the Registry up to September 1962. Assessment made in December 1964

\begin{tabular}{|c|c|c|c|c|c|c|}
\hline & & & & Alive & Fatal & Total \\
\hline \multicolumn{4}{|c|}{$\begin{array}{l}\text { Leukaemias } \ldots \\
\text { Non-leukaemic reticuloendothelial tumours }\end{array}$} & \multirow{11}{*}{$\begin{array}{r}0 \\
31 \\
50 \\
17 \\
24 \\
57 \\
13 \\
23 \\
32 \\
3 \\
25 \\
3\end{array}$} & \multirow{11}{*}{$\begin{array}{r}250 \\
41 \\
102 \\
51 \\
4 \\
50 \\
33 \\
13 \\
12 \\
18 \\
17 \\
25\end{array}$} & \multirow{11}{*}{$\begin{array}{r}250 \\
72 \\
152 \\
68 \\
28 \\
107 \\
46 \\
36 \\
44 \\
21 \\
42 \\
28\end{array}$} \\
\hline Gliomas . . . & . & .. & . & & & \\
\hline Sympathetic tumours & . & . & .. & & & \\
\hline Retinoblastomas $\quad \ldots$ & . & . & .. & & & \\
\hline Connective-tissue tumo & & . & . & & & \\
\hline Wilms's tumours & .. & .. & . & & & \\
\hline Epithelial tumours .. & . & .. & .. & & & \\
\hline Teratomas . . & . & . & . & & & \\
\hline Ewing's tumours $\ldots$ & . & $\ldots$ & .. & & & \\
\hline Miscellaneous & . & . & . & & & \\
\hline \multirow[t]{2}{*}{ Malignant unclassified } & $\cdots$ & $\cdots$ & $\cdots$ & & & \\
\hline & & & & $278(31 \%$ & $616(69 \%)$ & 894 \\
\hline
\end{tabular}

\section{Diagnosis}

Are these patients diagnosed as early as possible? Considering that the symptoms are often vague and that a general practitioner sees on an average only one child with a tumour every 20 years, it is perhaps surprising that these children are admitted to hospital more quickly than adults with such common tumours as carcinomas of the breast or cervix (AitkenSwan and Paterson, 1959 ; Campbell et al., 1961). An analysis of the pre-admission histories of children included in the Registry over a period of five years rarely revealed unreasonable delay either by the parents or by the general practitioner. Once they are in hospital $80 \%$ are diagnosed within one week and $90 \%$ within one month. It is unrealistic to expect anything better than this, and little benefit would accrue from any policy of making doctors or the lay public more aware of 